\title{
The Effectiveness of Infiltration against Roof Insulation aimed at Low Income Housing Retrofits for Different Climate Zones in Jordan
}

\author{
Aiman ALBATAYNEH ${ }^{1 *}$, Mohammad N. ASSAF², Mustafa JARADAT ${ }^{3}$, \\ Dariusz ALTERMAN ${ }^{4}$ \\ ${ }^{1-3}$ Energy Engineering Department, School of Natural Resources Engineering and Management, \\ German Jordanian University, Amman, Jordan \\ ${ }^{4}$ Priority Research Centre, The University of Newcastle, NSW, Australia
}

\begin{abstract}
Building energy demand for heating and cooling has a complicated relationship with different environmental conditions surrounding the building sector. Many projects aiming to improve thermal performance in existing buildings in Jordan suggest that roof insulation will improve thermal performance. In this study we try to prove that minimizing building infiltration is more effective and provides a lower cost solution in low-income houses in Jordan. This work introduces a comparative analysis of the infiltration rate and insulation techniques applied to standalone low-income houses in Jordan to identify the energy efficiency of those techniques for different climate zones in the country. A building simulation presenting the common building configuration used in was developed to test the effectiveness of various insulation scenarios (Roof, Wall, Roof and wall together) and infiltration rate scenarios. The results show that in different climates the reduction of infiltration to half $(0.75$ air changes per hour (ACH)) shows a similar potential to reduce energy demand as 10 or $12.5 \mathrm{~cm}$ roof or wall insulation. Also, the reduction of infiltration rate to a low level $(0.25 \mathrm{ACH})$ can decrease energy demand more effectively than $12.5 \mathrm{~cm}$ insulation in the roof or walls.
\end{abstract}

Keywords - Buildings retrofits; infiltration rate; low energy building; thermal insulation

\section{INTRODUCTION}

Buildings have been occupying a significant fraction of total energy demand, even in industrial countries. For instance, dwelling buildings constitute $22 \%$ and $27.2 \%$ of the energy expended in the USA [1] and Europe [2], respectively. Therefore, the building sector is considered one of the highest greenhouses gases producers. In a non-industrial country like Jordan, the household sector consumed $21.5 \%$ of total energy and $45.4 \%$ of total electrical power in 2019 as the broader consumer sector of electricity [3].

Reducing energy demand has gained significant attention from both academic and governmental echelons engaging much of the research and developing several laws and strategies. A large room of those works focuses on reducing the heat transfer through the building exterior.

\footnotetext{
* Corresponding author.

E-mail address: Aiman.Albatayneh@gju.edu.jo 
Roof and external walls form the highest proportion of the building's envelope; thus, several research projects held to investigate the effects of different materials and thermal insulation techniques on energy demand in the building. Optimizations of thermal insulation thickness, solar reflectance, and infrared emissivity values of building's envelope, consider the numerous useful passive measures for decreasing the cooling and heating loads [4]-[8].

Heat transfer through roofs and external walls is affected by various factors. Solar radiation absorption and infrared radiation controls the heat transfer of the roof during the daytime. Contrariwise, those factors have a limited notable effect in walls where convective dominate the wall heat transfer [9]-[11]. This dissimilarity transpires because roofs are exposed to intense solar radiation at an enormously higher angle. Moreover, roofs have a more superior landscape to the surrounding environment than any external wall, thus it will lose significantly more heat to the surrounding environment through infrared emission. The effect of using local materials for roof insulation of individual houses built of clay and straw on energy demand was investigated in a dry tropical climate. The simulation results indicate that $6.2 \%$ and $12.1 \%$ of energy saving can be achieved by using $1.5 \mathrm{~cm}$ thickness of redwood and a mixture of natural fiber with lime cement, respectively [12].

Convection strongly depends on wind direction; the convective heat loss coefficient is highest for upwind walls, followed sequentially by roofs, crosswind walls, and downwind walls, [13], [14]. In this sense, air infiltration composes a significant source of convection in the building sector where the air is exchanged between inside and outside through cracks and other unintentional openings. Besides reducing the thermal comfort of building occupants, this convection places an extra energy demand. Thus, controlling the infiltration rate through airtight design and the implementation of effective construction retrofits is identified as one of the vital components to reducing energy demand in both new and existing buildings. Various studies have been carried out to estimate the effect of infiltration on residential energy demand. Prior investigations have evaluated the energy wastage through ventilation processes, which found greater than $30 \%$ of energy is consumed in residences [15]. A study conducted in a moderately cold climate indicates that heating demand increases about $10 \mathrm{kWh} \mathrm{m}^{-2}$ each year due to air infiltration [16]. In a temperate climate, the building air leakage is estimated to raise the heating loads from $5 \mathrm{kWh} \mathrm{m}^{-2}$ to $20 \mathrm{kWh} \mathrm{m}^{-2}$ per year [17].

A recent study in Amman, the capital of Jordan, shows that a $50 \%$ reduction of infiltration rate will reduce the heating and cooling load by $19.4 \%$ by and lead to a $10 \%$ enhancement of thermal comfort in a building following the national building codes [18].

Simulation software were used to assess building thermal performance and most have issues in accurately capturing the behaviour of the building in order to calculate energy demands [19]-[23].

Although several studies on building energy demand have been held in Jordan, there is a lack of study focusing on low income housing. Some research concentrates on the Green building concept and how it can be achieved, and how can Jordanian building codes can be enhanced based on international green building codes such as Leadership in Energy and Environmental Design (LEED) [24]-[26].

There any many factors affecting the accuracy of the simulation which are difficult to capture by the simulation tools such as; occupant behavior, the wide range of construction materials and different thermal comfort models [27]-[39].

Other studies have converged on developing strategies to reach a zero-energy building [40], [41]. Thus, this work has investigated the potential of reducing the cooling and heating load for typical low-income houses through the creation of several scenarios of thermal insulation (roof, walls and both of them together) and reducing the infiltration rate. 


\section{Methodology}

This research aimed to highlight the importance of energy conservation and energy efficiency concepts, their measures opportunities to optimize the building into low-energy or zero-energy building by performing an energy audit and mapping the energy demand in the building by using DesignBuilder software. Recently, several simulation technologies were used to evaluate any early design decisions by using simulation tools and software to quickly model and test alternatives.

Using DesignBuilder as smart and real-time microclimate control software provides advanced modeling tools in an easy-to-use interface to assist in performing this analysis, it uses the EnergyPlus dynamic simulation engine to generate range of environmental performance data such as: monthly and annual energy demand, maximum summertime temperatures and HVAC component sizes. This enables to use this software to develop comfortable and energy-efficient building designs from concept through to completion, investigate the impact of various energy saving measures.

DesignBuilder software used in this study to build base simulation model that firstly accurate calculations of lighting and cooling systems loads for the current situation of the building including nearly identical building construction and materials details under realistic weather data at hourly time steps in region of the case studies, by analysing the building's components which affect the systems.

A base simulation model was built through DesignBuilder software, including construction and materials details of building envelope which were designed, building type and activities, working hours and days, the building locations and orientation, opening types including windows and wall materials along with the real site weather data at hourly time steps in region of different climate zones.

The baseline model is a typical residential low income building with a total area of $186 \mathrm{~m}^{2}$ and oriented with the long axis facing the south-north axis (Fig. 1).

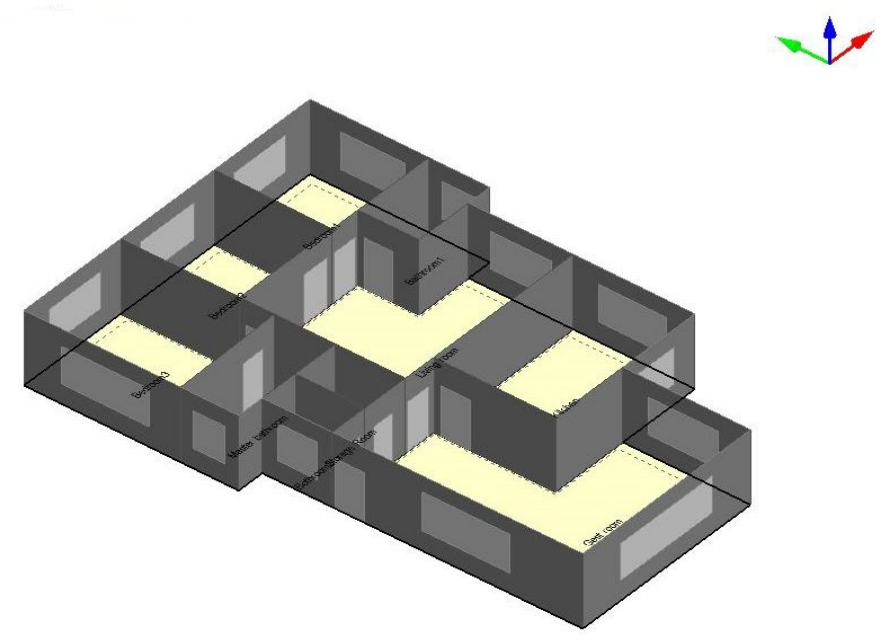

Fig. 1. Overview of baseline building. 
To assess the performance of various infiltration rates and thermal insulation (wall and roof) scenarios, dynamic simulations were executed in DesignBuilder software. A model of a stand-alone family house representing the most common low-income building in Jordan was used as a baseline. This baseline model was tested in four Jordanian climate zones. The first one is the warm semi-arid Mediterranean climate, with more heat needs similar to the larger Jordanian region. The second is the hot Saharan Mediterranean with the most cooling needs, this climate is similar to the main city of Aqaba. The third zone is the cool arid Mediterranean, where the need is for both heating and cooling, similar to the major cities of Zarqa and Al-Mafraq. The fourth one is the warm Sahara Mediterranean; this zone covers small towns such as Ruwished, Jafr, and Azraq, with mostly cooling needs and a notable heating load. The heating and cooling consumption in this building were measured in different climate zones, and the annual energy savings of heating and cooling for the previously mentioned elements scenarios were calculated.

The roof is constructed of a $30 \mathrm{~cm}$ reinforced concrete slab and $10 \mathrm{~cm}$ lightweight concrete, with cement plastering finish on the inside and waterproofing bitumen roll finish on the outside (the $U$-value of the whole roof was $1.067 \mathrm{~W} \mathrm{~m}^{-2} \mathrm{~K}^{-1}$ ). The walls are made of double $10 \mathrm{~cm}$ hollow concrete block spreading with a $5 \mathrm{~cm}$ air gap with plaster finish on both inside and outside (overall $U$-value of $1.867 \mathrm{~W} \mathrm{~m}^{-2} \mathrm{~K}^{-1}$ ). Single glazing with metal frame windows represented $30 \%$ of the surface area in the external walls area, and we simulated it without external shading or neighbouring handle breaks.

For the insulation scenarios, extruded polystyrene (XPS) material was used which have the following properties: conductivity $0.034 \mathrm{~W} \mathrm{~m}^{-1} \mathrm{~K}^{-1}$, specific heat $1400\left(\mathrm{~J} \mathrm{~kg}^{-1} \mathrm{~K}^{-1}\right)$, density $35 \mathrm{~kg} \mathrm{~m}^{-3}$. Windows type is double glass Generic with Buck Frame $(U$-Value $=0.85)$.

The energy performance of adding the insulation layer with different thickness $(2.5,5,7.7$, $10,12.5 \mathrm{~cm}$ ) was tested individually for the roof and walls, and then for both. In total 15 different scenarios were created as explained in Table 1.

TABLE 1. U-VALUE OF RoOF AND WALl FOR EACH InSUlation SCENARIOS

\begin{tabular}{lll}
\hline Case, cm & $\begin{array}{l}\text { Roof, } \\
\text { W m }\end{array} \mathbf{K}^{-\mathbf{1}}$ & $\begin{array}{l}\text { Wall, } \\
\mathbf{W ~ m}^{-1} \mathbf{K}^{-\mathbf{1}}\end{array}$ \\
\hline Baseline & 1.067 & 1.867 \\
Roof 2.5 & 0.597 & 1.867 \\
Roof 5 & 0.415 & 1.867 \\
Roof 7.5 & 0.318 & 1.867 \\
Roof 10 & 0.258 & 1.867 \\
Roof 12.5 & 0.217 & 1.867 \\
Wall 2.5 & 1.065 & 0.787 \\
Wall 5 & 1.065 & 0.498 \\
Wall 7.5 & 1.065 & 0.365 \\
Wall 10 & 1.065 & 0.288 \\
Wall 12.5 & 1.065 & 0.237 \\
All (roof and walls) 2.5 & 0.597 & 0.787 \\
All (roof and walls) 5 & 0.415 & 0.498 \\
All (roof and walls) 7.5 & 0.318 & 0.365 \\
All (roof and walls) 10 & 0.258 & 0.288 \\
All (roof and walls) 12.5 & 0.217 & 0.237 \\
\hline
\end{tabular}


For the infiltration rate, it was simulated to be 1.5 air changes per hour $(\mathrm{ACH})$ in the baseline, the effect of reducing it was measured in four different values $(1,0.75,0.5$ and $0.25 \mathrm{ACH})$.

These assumptions were implemented through this analysis. The building is a typical Jordanian building occupied all year where the temperature sets at $20-21^{\circ} \mathrm{C}$ in winter months and $25-26^{\circ} \mathrm{C}$ in summer months. The internal heat gain from occupants; home appliances and LED lighting were fixed at 500 Watts. External shading on east and west windows in summer months and no external shading were implemented in the southern and the northern windows.

\section{RESULTS AND DiSCUSSION}

Heating and cooling consumption of the baseline building were studied in different Jordanian climate zones. Thus, significant varied found in its relevant energy needs Fig. 2. The cooling needs dominant in most of the climate zones; Zone number one is the only case where the heating load shows a higher need than cooling.

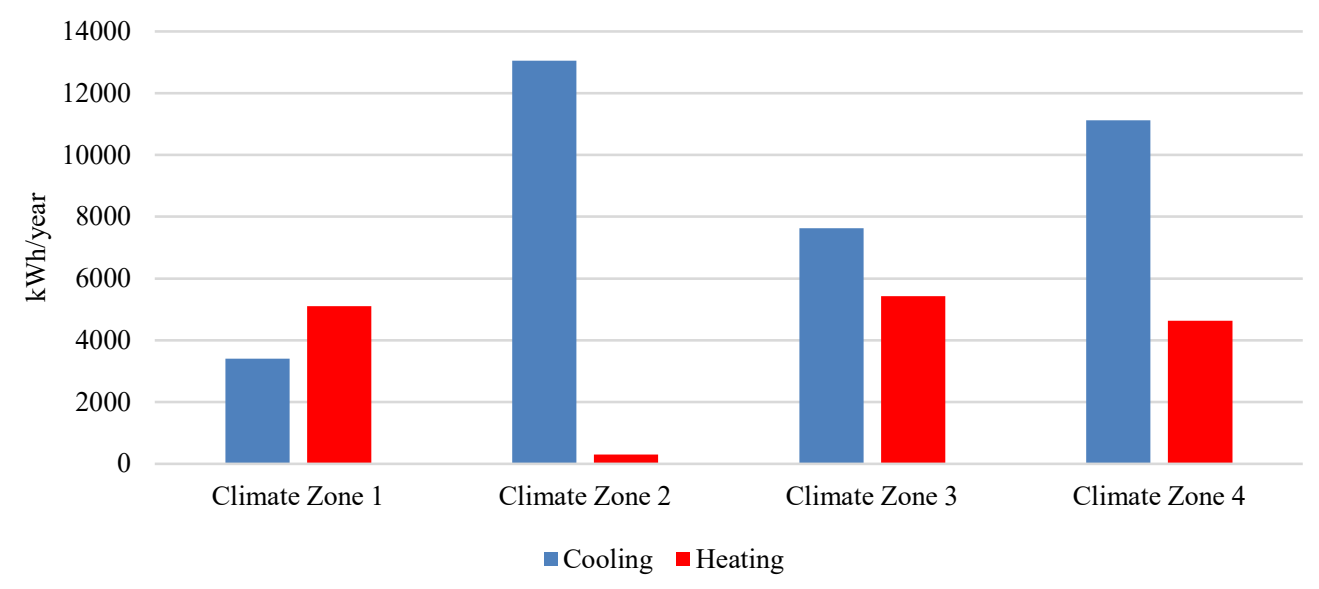

Fig. 2. Annual cooling and heating consumption in the baseline in different climate zones.

Table 2 shows the total energy demand of heating and cooling per unit of area in different climate zones, and with the various insulation and infiltration rate scenarios.

Fig. 3 presents the annual total energy savings of the heating and cooling accrued for each insulation scenario; they are the outcome of subtracting the heating and cooling consumption from the baseline model. In all of the cases, energy saving is directly proportional to the increase in insulation thickness. Significant energy gain has happened by adding 2.5 and $5 \mathrm{~cm}$ of insulation. After that, the increasing thickness shows only a slight rise in energy saving. Roof insulation shows more ability to reduce the cooling load while wall insulation was more powerful in heating consumption minimization.

Decreasing the infiltration rate introduces a significant reduction in energy demand, mainly in the heating need except in climate zone two, where the heating load is almost negligible in the baseline. In all of the climate zones, the infiltration rate limiting is directly proportional to energy saving (see Fig. 4). In climate zone number one, the infiltration reduction to 0.25 
air changes per hour $(\mathrm{ACH})$ led to a slight increase in the cooling needs. However, the heating needs decreasing, in this case.

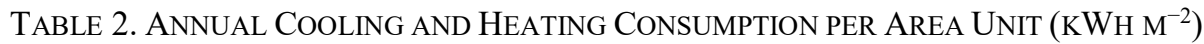

\begin{tabular}{lllll}
\hline Case & Zone 1 & Zone 2 & Zone 3 & Zone 4 \\
\hline Baseline & 45.7 & 71.8 & 70.3 & 84.7 \\
Roof 2.5 & 41.1 & 65.7 & 64.2 & 76.4 \\
Roof 5 & 39.1 & 63.2 & 61.7 & 72.8 \\
Roof 7.5 & 38.1 & 61.8 & 60.3 & 70.9 \\
Roof 10 & 37.4 & 60.9 & 59.4 & 69.7 \\
Roof 12.5 & 36.9 & 60.3 & 25.5 & 25.5 \\
Wall 2.5 & 39.6 & 63.7 & 61.5 & 75.0 \\
Wall 5 & 37.8 & 61.2 & 58.9 & 72.1 \\
Wall 7.5 & 36.8 & 59.9 & 57.5 & 70.5 \\
Wall 10 & 36.2 & 59.0 & 56.6 & 69.4 \\
Wall 12.5 & 35.6 & 58.2 & 55.8 & 68.5 \\
All 2.5 & 34.5 & 57.0 & 54.9 & 66.0 \\
All 5 & 30.4 & 51.6 & 49.3 & 58.9 \\
All 7.5 & 28.1 & 48.6 & 46.1 & 54.9 \\
All 10 & 26.6 & 46.5 & 44.0 & 52.2 \\
All 12.5 & 25.5 & 45.0 & 42.5 & 50.3 \\
1 ACH & 39.7 & 65.5 & 62.5 & 76.2 \\
0.75 ACH & 36.9 & 62.5 & 58.8 & 72.1 \\
0.5 ACH & 34.1 & 59.6 & 55.3 & 67.9 \\
0.25 ACH & 31.6 & 57.0 & 52.1 & 63.9 \\
\hline
\end{tabular}

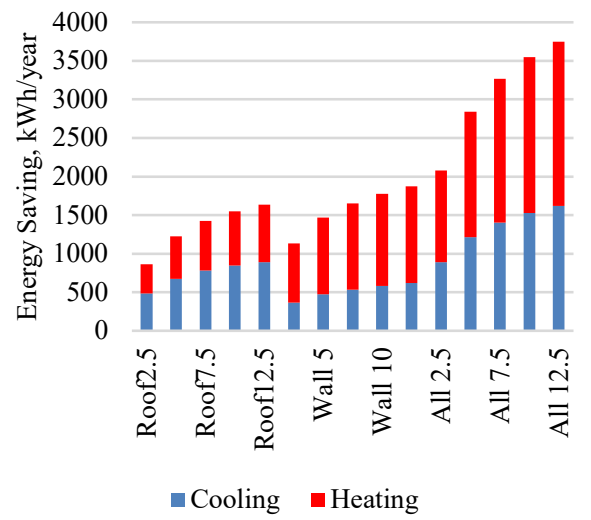

Zone 1

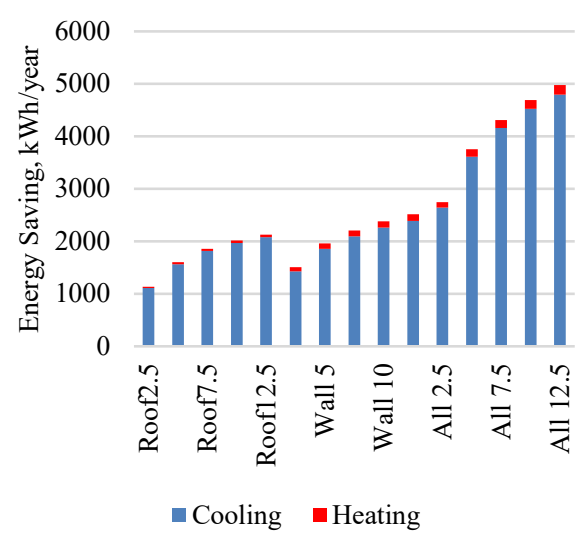

Zone 2 


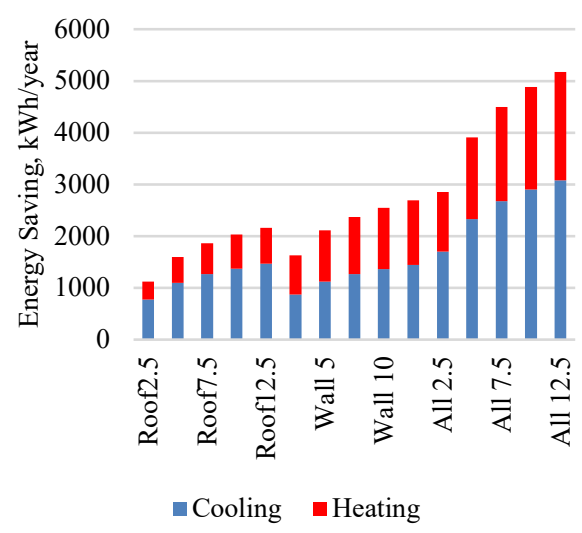

Zone 3

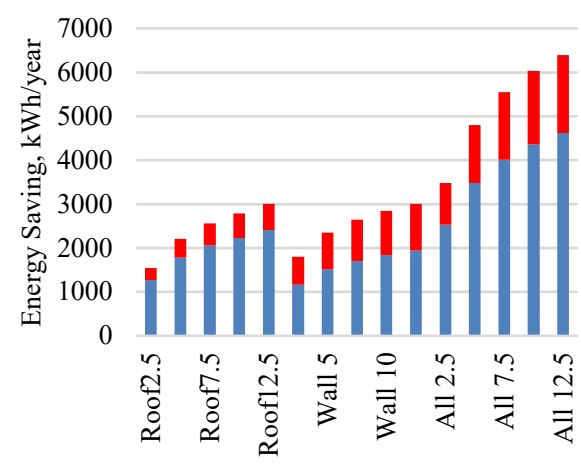

- Cooling -Heating

Zone 4

Fig. 3. Annual cooling and heating energy saving from thermal insulation in different climate zones.

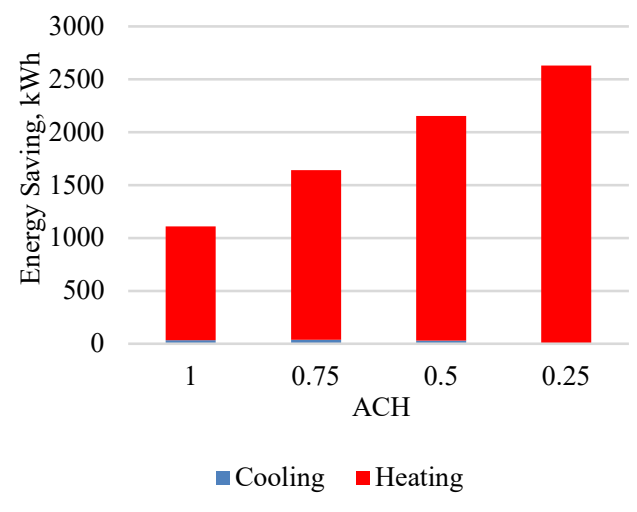

Zone 1

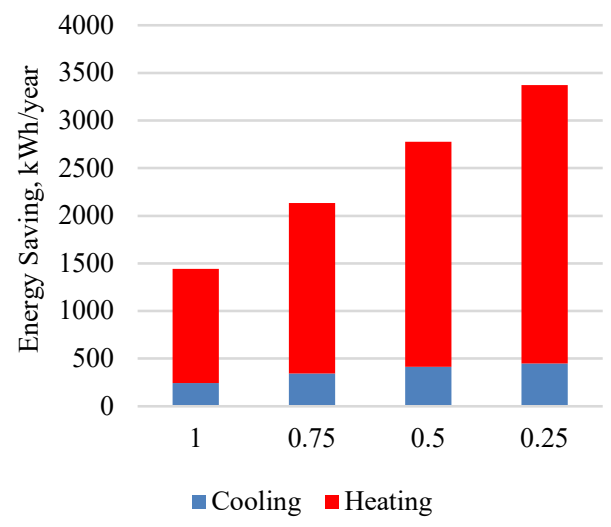

Zone 3

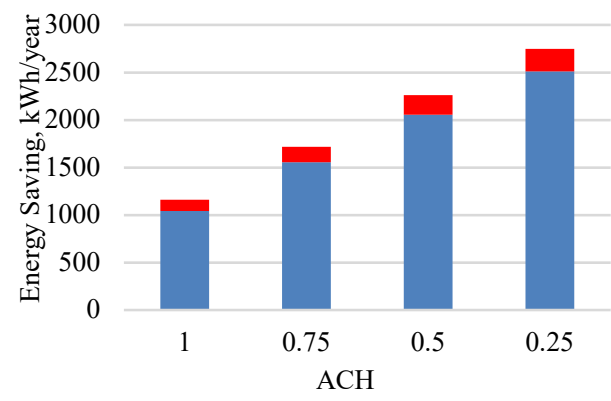

- Cooling Heating

Zone 2

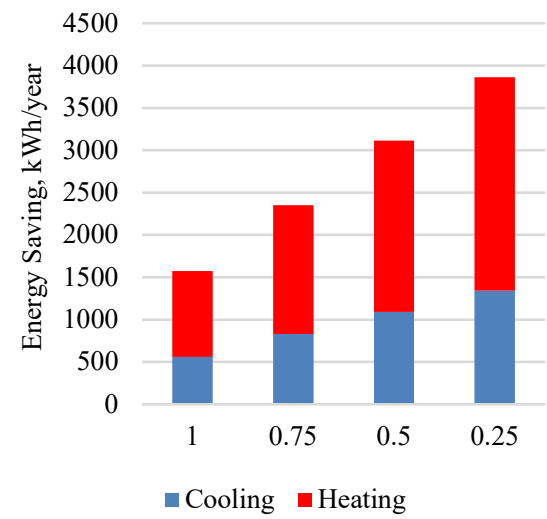

Zone 4

Fig. 4. Annual cooling and heating energy saving from infiltration rate reduction $(\mathrm{ACH})$ in different climate zones. 
$2020 / 24$

Fig. 5-8 present the energy saving percent for each climate, comparing the saving of the thermal insulation and infiltration rate. In climate zone one (Fig. 5) reducing the infiltration rate to the half $(0.75 \mathrm{ACH})$ can result in $20 \%$ energy saving which requires around $10 \mathrm{~cm}$ or $12.5 \mathrm{~cm}$ insulation of wall and roof, respectively to have same effect. The high insulation case $(12.5 \mathrm{~cm}$ for both walls and roof) results in $45 \%$ energy saving while infiltration reduction to 0.25 air changes per hour $(\mathrm{ACH})$ can save $31 \%$ of the heating and cooling consumption.
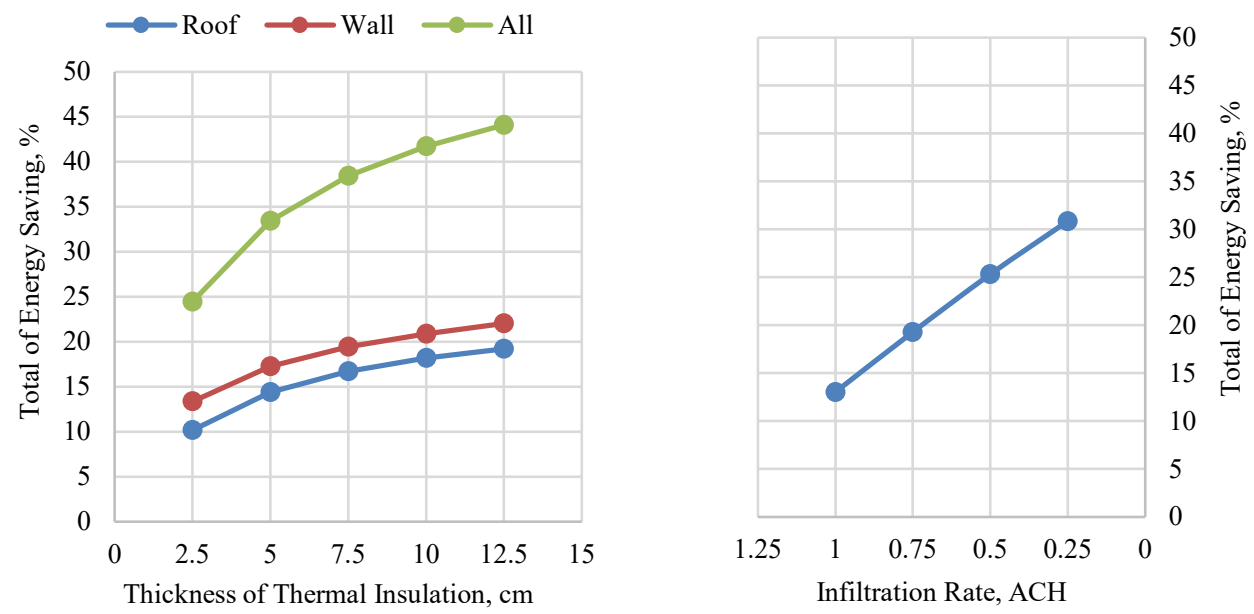

Fig. 5. Annual energy saving present from insulation (left) and infiltration rate (right) in climate zone 1.

Fig. 6 shows how in enormously hot climate with a short of heating demands, the energy saving pattern. The infiltration rate reduction shows less capacity to decrease the energy demand compared with its capacity in the other climate zones. In so far as the infiltration in summer nights can reduce the internal temperature in the building and carry out the heat. However, the energy saving due to infiltration rate reduction is still meaningful.

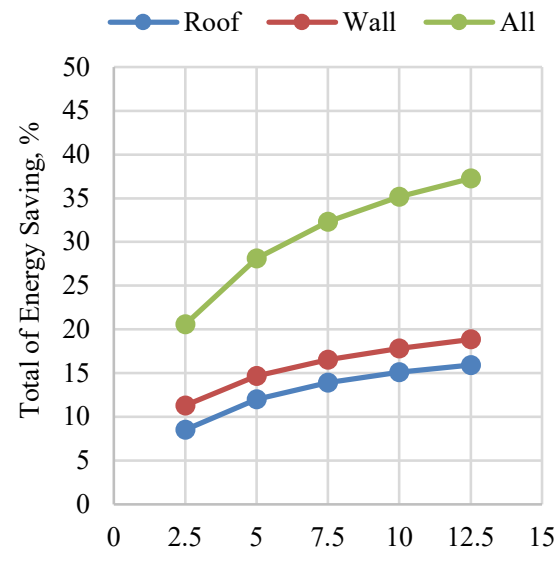

Thickness of Thermal Insulation, $\mathrm{cm}$

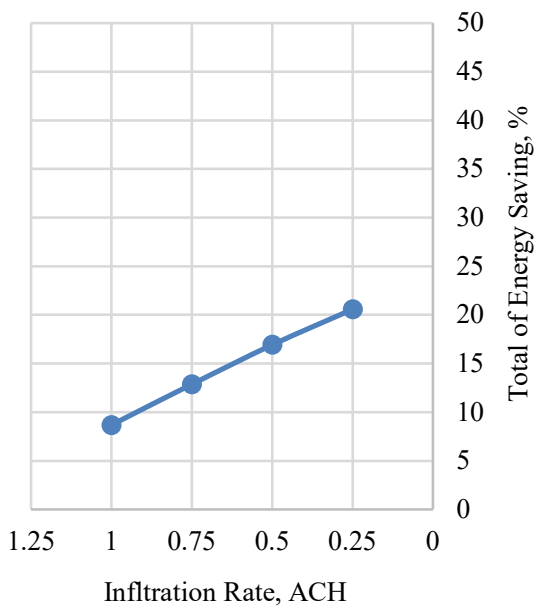

Fig. 6. Annual energy saving present from insulation (left) and infiltration rate (right) in climate zone 2. 
The energy saving percentages show a similar shape in the third and fourth climate zones, although in the fourth climate zone, the walls and roof insulation show an almost analogous energy saving present. Reducing the infiltration rate to 0.25 air changes per hour (ACH) provides better energy saving than neither roof insulation, nor walls insulation. In addition, it has approximately the same effect as adding $5 \mathrm{~cm}$ of walls and roof insulation together (Fig. 7 and Fig. 8).
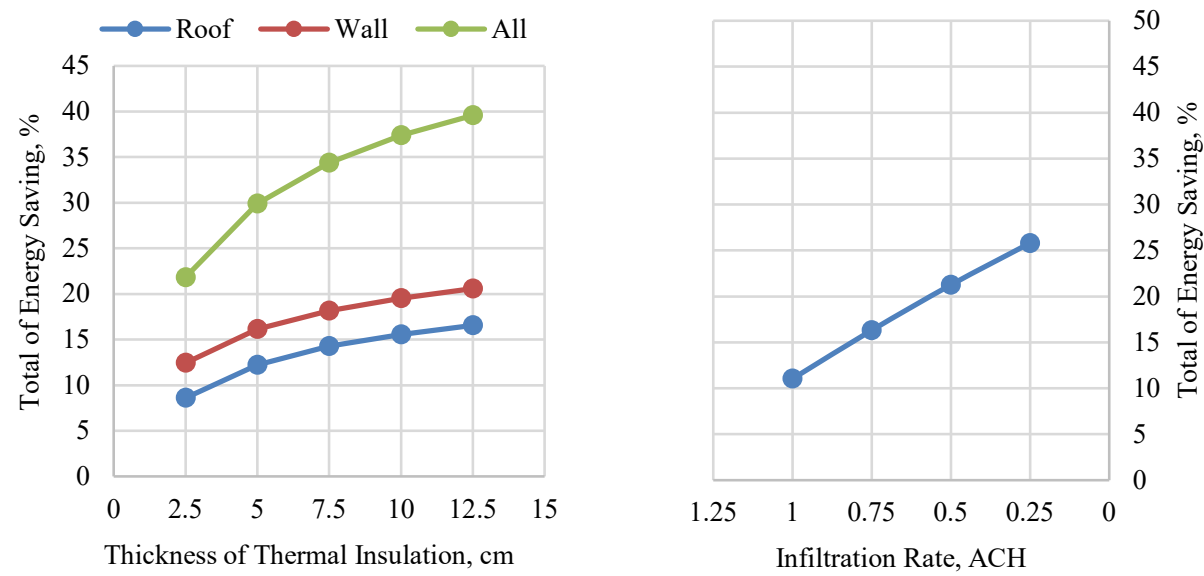

Fig. 7. Annual energy saving present from insulation (left) and infiltration rate (right) in climate zone 3.
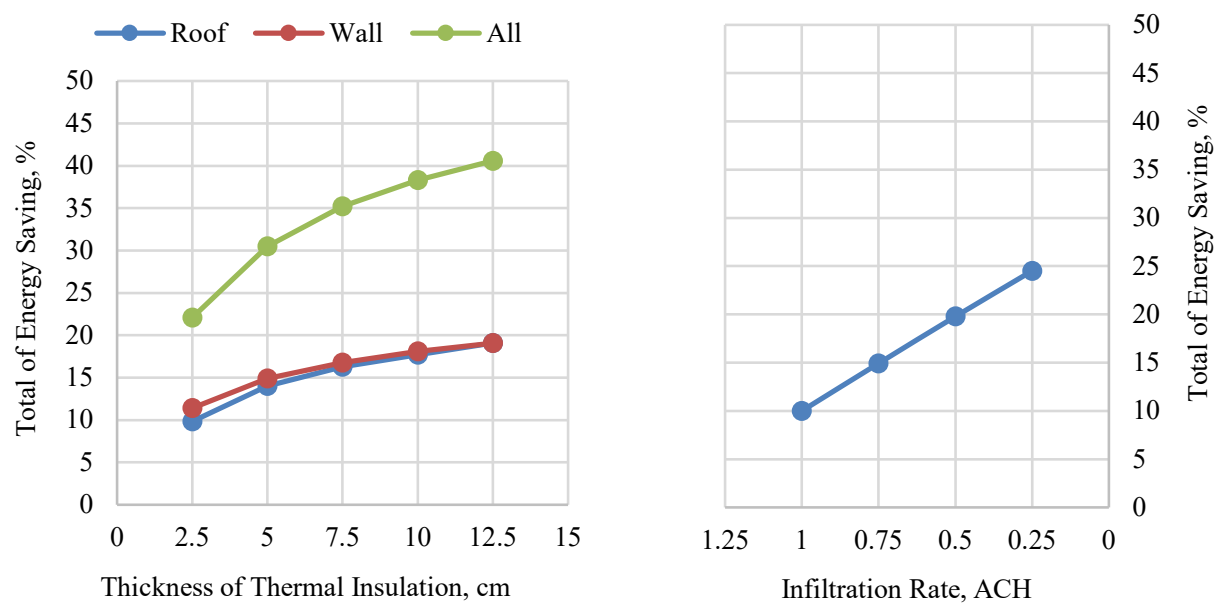

Fig. 8. Annual energy saving present from insulation (left) and infiltration rate (right) in climate zone 4.

The final results show that in different climates the reduction of infiltration to half $(0.75$ air changes per hour $(\mathrm{ACH})$ ) shows a similar potential to reduce energy demand as 10 or $12.5 \mathrm{~cm}$ roof or wall insulation. Also, the reduction of infiltration rate to a low level $(0.25 \mathrm{ACH}) \mathrm{can}$ decrease energy demand more effectively than $12.5 \mathrm{~cm}$ insulation in the roof or walls. 
When air leaks into building from outside, called infiltration; when conditioned indoor air leaks out, it's exfiltration. Both can occur through cracks around windows, doors, dampers, and skylights, or whenever a door or window is opened. The amount of infiltration and exfiltration that occurs is obviously affected by the types of openings your building has along with how good the weatherproofing is, but there are other factors as well. The building's structure, the direction and duration of the wind, and pressure differences inside and outside the building also affect air leakage.

The materials used for infiltrations such as; weather-strip doors and windows; caulk around window frames (exterior and interior) and rehang misaligned doors and windows frames. The cost of materials used for minimizing the infiltration very low compared with the cost of roof insulations which can be around $1 / 100$ of the roof insulation cost.

\section{CONCLusion}

This research investigates the energy performance of thermal insulation and infiltration rate with different scenarios in a low-income residential building under different climate zones in Jordan. This study has compared the energy efficiency of a low-cost option (infiltration rate) with a more expensive one (thermal insulation). For that, different scenarios of walls and roof insulation and infiltration rate were created and tested in different Jordanian climates. The results show that both thermal insulation and infiltration rate retrofit can lead to significant energy savings. In the same climate zone, thermal insulation provides more capacity in reducing the cooling needs, while reducing the infiltration rate shows more ability to reduce the heating load. This can be explained as the infiltration rate phenomena response of carrying the external cold air into the internal building environment, which significantly increases the heating load during winter. In contrast, the same air exchange has a less significant effect on the cooling load during the summer. For the Jordanian low-income householder, the heating load consists of more economic pressure since they need to search for an alternative source of heating like natural gas or heavy oil. Also, the cooling load can be reduced using techniques such as shading and night ventilation.

For the thermal insulation, the walls insulation provides more potential to reduce energy demand than roof insulation.

\section{ACKNOWLEDGMENT}

The authors are thankful for the seed grant fund (SNERM 04/2018) provided by the deanship of graduate studies and research at the German Jordanian University.

\section{REFERENCES}

[1] United State Departament of Energy. 2011 Buildings Energy Data Book [Online]. [Accessed 06.01.2020]. Available: https://ieer.org/wp/wp-content/uploads/2012/03/DOE-2011-Buildings-Energy-DataBook-BEDB.pdf

[2] Europa Union. EU Energy in Figures Statistical Pocketbook 2019. [Online]. [Accessed 06.01.2020]. Available: https://op.europa.eu/en/publication-detail/-/publication/e0544b72-db53-11e9-9c4e-01aa75ed71a1

[3] Ministry of Energy and Mineral Resources, Energy 2019 - Facts \& Figures. 2019. [Online]. [Accessed 06.01.2020]. Available: https://www.memr.gov.jo/EchoBusV3.0/SystemAssets/PDFs/EN/BroshorEn2019.pdf

[4] Bolattürk A. Optimum insulation thicknesses for building walls with respect to cooling and heating degree-hours in the warmest zone of Turkey. Building and environment 2008:43(6):1055-1064.

https://doi.org/10.1016/j.buildenv.2007.02.014 
[5] Gentle A. R., Aguilar J. L. C., Smith G. B. Optimized cool roofs: Integrating albedo and thermal emittance with $R$ value. Solar Energy Materials and Solar Cells 2011:95(12):3207-3215. https://doi.org/10.1016/j.solmat.2011.07.018

[6] Shi Z., Zhang X. Analyzing the effect of the longwave emissivity and solar reflectance of building envelopes on energysaving in buildings in various climates. Solar Energy 2011:85(1):28-37. https://doi.org/10.1016/j.solener.2010.11.009

[7] Chen J., Peng Z., Yang P. P. J. The Energy Performance Evaluation of Roof Retrofit Under Uncertainties for the Shanghai's Worker Village. Energy Procedia 2019:158:3170-3176. https://doi.org/10.1016/j.egypro.2019.01.1020

[8] Fantucci S., Serra V. Investigating the performance of reflective insulation and low emissivity paints for the energy retrofit of roof attics. Energy Buildings 2019:182:300-310. https://doi.org/10.1016/j.enbuild.2018.10.003

[9] Nowak H. The longwave radiative heat transfer of the building envelopes. Infrared physics 1991:32:357-363. https://doi.org/10.1016/0020-0891(91)90124-X

[10] Chwieduk D. A. Recommendation on modelling of solar energy incident on a building envelope. Renewable Energy 2009:34(3):736-741. https://doi.org/10.1016/j.renene.2008.04.005

[11] Kaşka Ö., Yumrutaş R. Experimental investigation for total equivalent temperature difference (TETD) values of building walls and flat roofs. Energy Conversion Management 2009:50(11):2818-2825. https://doi.org/10.1016/j.enconman.2009.06.027

[12] Toguyeni D. Y., et al. Rousse, and Buildings. Study of the influence of roof insulation involving local materials on cooling loads of houses built of clay and straw. Energy Buildings 2012:50:74-80.

https://doi.org/10.1016/j.enbuild.2012.03.021

[13] Emmel M. G., Abadie M. O., Mendes N. J. E. New external convective heat transfer coefficient correlations for isolated low-rise buildings. Energy Buildings 2007:39:3:335-342. https://doi.org/10.1016/j.enbuild.2006.08.001

[14] Palyvos J. A. A survey of wind convection coefficient correlations for building envelope energy systems' modeling. Applied Thermal Engineering 2008:28(8-9):801-808. https://doi.org/10.1016/j.applthermaleng.2007.12.005

[15] Orme M. J. E. Estimates of the energy impact of ventilation and associated financial expenditures. Energy Buildings 2001:33(3):199-205. https://doi.org/10.1016/S0378-7788(00)00082-7

[16] Aurlien T. Performing intermediate checks and early-stage testing of airtightness. REHVA Journal 2013:01:15.

[17] Thomsen K. E., Rose J., Aggerholm S. The final recommendations of the ASIEPI project: How to make EPBregulations more effective? ASIEPI, 2010.

[18] Almarzouq A. Sakhrieh A. Effects of glazing design and infiltration rate on energy consumption and thermal comfort in residential buildings. Thermal science 2019:23(5B):2951-2960. https://doi.org/10.2298/TSCI170910073A

[19] Albatayneh A., et al. Warming Issues Associated with The Long Term Simulation of Housing Using CFD Analysis. Journal of Green Building 2016:1(2):57-74. https://doi.org/10.3992/jgb.11.2.57.1

[20] Albatayneh A., Alterman D., Page A. Adaptation the Use of CFD Modelling for Building Thermal Simulation. Proceedings of the 2018 International Conference on Software Engineering and Information Management 2018:6872. https://doi.org/10.1145/3178461.3178466

[21] Albatayneh A., et al. The Significance of Time Step Size in Simulating the Thermal Performance of Buildings. Advances in Research 2015:5(6):1-12. https://doi.org/10.9734/AIR/2015/20223

[22] Albatayneh A., et al. Discrepancies in Peak Temperature Times using Prolonged CFD Simulations of Housing Thermal Performance. Energy Procedia 2017:115:253-264. https://doi.org/10.1016/j.egypro.2017.05.023

[23] Albatayneh A., et al. An Alternative Approach to the Simulation of Wind Effects on the Thermal Performance of Buildings. International Journal of Computational Physics 2018:1:35-44. https://doi.org/10.29167/A1I1P35-44

[24] Hassouneh K., Al-Salaymeh A., Qoussous J. Energy audit, an approach to apply the concept of green building for a building in Jordan. Sustainable Cities Society 2015:14:456-462. https://doi.org/10.1016/i.scs.2014.08.010

[25] Ali H. H., Al Nsairat S. F. Developing a green building assessment tool for developing countries-Case of Jordan. Building environment 2009:44(5):1053-1064. https://doi.org/10.1016/j.buildenv.2008.07.015

[26] Alshorman A. A., et al. Validation of Jordanian Green Building Based on LEED Standard for Energy Efficiency Methodology. Jordan Journal of Mechanical Industrial Engineering 2018:12(1).

[27] Albatayneh A., et al. Development of a new metric to characterise the buildings thermal performance in a temperate climate. Energy for Sustainable Development 2019:51:1-2. https://doi.org/10.1016/j.esd.2019.04.002

[28] Albatayneh A., et al. The Significance of the Adaptive Thermal Comfort Limits on the Air-Conditioning Loads in a Temperate Climate. Sustainability 2019:11(2):328. https://doi.org/10.3390/su11020328

[29] Albatayneh A., et al. The Significance of Building Design for the Climate. Environmental and Climate Technologies 2018:22:165-178 https://doi.org/10.2478/rtuect-2018-0011

[30] Albatayneh A., et al. The Impact of the Thermal Comfort Models on the Prediction of Building Energy Consumption. Sustainability 2018:10(10):3609. https://doi.org/10.3390/su10103609

[31] Albatayneh A., et al. The Significance of Temperature Based Approach Over the Energy Based Approaches in the Buildings Thermal Assessment. Environmental and Climate Technologies 2017:19(1):39-50. https://doi.org/10.1515/rtuect-2017-0004

[32] Albatayneh A., Alterman D., et al. Thermal Assessment of Buildings Based on Occupants Behavior and the Adaptive Thermal Comfort Approach. Energy Procedia 2017:115:265-271. https://doi.org/10.1016/j.egypro.2017.05.024 
[33] Albatayneh A., et al. Assessment of the Thermal Performance of Complete Buildings Using Adaptive Thermal Comfort. Procedia-Social and Behavioral Sciences 2016:6:655-661. https://doi.org/10.1016/j.sbspro.2015.12.051

[34] Albatayneh A., et al. Temperature versus energy based approaches in the thermal assessment of buildings. Energy Procedia 2017:128:46-50. https://doi.org/10.1016/j.egypro.2017.09.013

[35] Albatayneh A., et al. The Influence of Building's Orientation on the Overall Thermal Performance. Environmental Science \& Sustainable Development 2018:31:63-79.

[36] Albatayneh A., et al. Renewable Energy Systems to Enhance Buildings Thermal Performance and Decrease Construction Costs. Energy Procedia 2018:152:312-317. https://doi.org/10.1016/j.egypro.2018.09.138

[37] Albatayneh A., Assaf M., Jaradat M. The Benefits of Lower Thermal Mass Over Higher Thermal Mass Constructions in Sub-Mediterranean Climates. 2nd International conference on Applied Research in Engineering Science \& Technology, Budapest, Hungary, 2019.

[38] Albatayneh A., et al. The Significance of the Orientation on the Overall buildings Thermal Performance-Case Study in Australia. Energy Procedia 2018:152:372-377. https://doi.org/10.1016/j.egypro.2018.09.159

[39] Al-Addous M., Albatayneh A. Knowledge gap with the existing building energy assessment systems. Energy Exploration \& Exploitation 2020:38(3):783-794. https://doi.org/10.1177/0144598719888100

[40] Attia S., Al-Khuraissat M. Life Cycle Costing for a Near Zero Energy Building in Jordan: Initial Study. The 5th Architectural Jordanian International Conference. Jordan Engineers Association. 2016.

[41] Attia S., Zawaydeh S. Strategic decision making for zero energy buildings in Jordan [Online]. [Accessed 12.01.2020]. Available: https://orbi.uliege.be/bitstream/2268/202060/1/Syndicate\%20of\%20Engineers\%20ZEB\%20Jordan.pdf 